\title{
Asymptomatic bacteriuria and drug sensitivity patterns during pregnancy in an Indian Teaching Hospital
}

\author{
Authors \\ Ajit Kumar Bishoyi ${ }^{1}$, Pradip Kumar Panigrahi2*, Akankshya Sahu ${ }^{1}$ \\ Mahesh Chandra Sahu ${ }^{1}$ \\ ${ }^{1}$ Department of Obstetrics and Gynecology, IMS \& Sum Hospital, Siksha O Anusandhan Deemed to be \\ University, K8, Kalinga Nagar, Bhubaneswar 751003, Odisha, India \\ ${ }^{2}$ Medical Research laboratory, IMS \& Sum Hospital, Siksha O Anusandhan Deemed to be University, K8, \\ Kalinga Nagar, Bhubaneswar 751003, Odisha, India \\ *Corresponding Author

\section{Dr Pradip Kumar Panigrahi} \\ Associate Professor, Department of Obstetics and Gynaecology, IMS \& Sum Hospital, IMS and SUM \\ hospital, Bhubaneswar, India \\ Email:panigrahypradip@yahoo.co.in

Abstracts
Background: In pregnant women UTI is a major cause for complications during carrying period. It can
be solved by proper antibiotic therapy, but without culture sensitivity reveals multi drug resistance
strength in empirical therapy.
Materials \& Method: Urine samples were collected from UTI pregnant women attending at Out Patients
Department of Obstetrics and Gynaecology. Then samples were cultured and identified the organisms
with respect to morphology and biochemical tests. Antibiotic sensitivity patterns were carried out with
prescribed antibiotics disc in disc diffusion method.
Result: The maximum UTI found on the age group of 30 -39 years. E.coli is the most organism followed
by S.aureus in this study.
Ceftriaxone and Cefixime was the most susceptible antibiotic for UTI in the pregnant women.
Conclusion: Routine microscopic and culture should be carried out in pregnant UTI women and before
empirical therapy culture sensitivity must be carried out to minimize the resistance organism.
Keywords: UTI, Resistant, Pregnant, antibiotics, E. coli.

\section{Introduction}

Urinary tract infections (UTI) are common women and it is very common during pregnancy due to hormonal and anatomo-physiological changes that facilitate the growth and dissemination of bacteria in the maternal urinary tract $^{[1]}$. From literatures, it is revealed that $5-10 \%$ of women suffer some kind of UTI during pregnancy ${ }^{[2]}$. The most common situation is Asymptomatic bacteriuria followed by acute cystitis and pyelonephritis ${ }^{[3]}$ If the proper treatment will not carried out then serious consequences for maternal and fetal health will be revealed $^{[1]}$. Due to short urethra and its anatomical 
proximity to the anal orifice, UTI are more prevalent in women ${ }^{[4,5]}$. The bacteria is the most causative organism for UTI which complicates pregnancy ${ }^{[6]}$. In the body Pregnancy causes numerous hormonal and mechanical changes. Ninety percentage of the pregnant females suffer urethral dialatation increasing the risk of urinary stasis and vesicouretral reflux, It start in the sixth week, with peak incidence during 22nd to 24th weeks $^{[7]}$. The pregnancy are additional factors to facilitate bacterial growth during glycosuria and aminoaciduria $^{[8]}$. Untreated leads to maternal and perinatal morbidity and mortality left pregnancy in UTI[9].The pregnancy is associated with low birth weight and premature delivery during untreated bacteriruia ${ }^{[10]}$, as pregnant women's have UTI is the common health problem ${ }^{[11]}$.

UTI is important for successful treatment and prevention of complications. However, the antibiotic-resistant urinary pathogens are increasing prevalence, an appropriate empirical agent is increasingly difficult. The clinical practice guidelines are reflected in 2010, which recommend using nitrofurantoin as a first-line agent in place of cotrimoxazole, owing to a rise in the occurrence of organisms resistant to the latter ${ }^{[12,13]}$. In the treatment of UTI is used resistance to other antimicrobials, also fluoroquinolones is increasing particularly, the prevalence of extended-spectrum-beta-lactamase (ESBL) is producing Enterobacteriaceae and multidrugresistant (MDR) Pseudomonas aeruginosa ${ }^{[14-16]}$. The urinalysis results consider the choice of antimicrobial agents should be preferably, the pathogen identification is allow, The susceptibility of microorganisms indicates to specific groups of antimicrobials in addition to antimicrobial susceptibility testing ${ }^{[17]}$. However, the antimicrobial agent is correct choice to treat UTI during pregnancy is complex because it requires full safety to maternal and fetal, in addition to gradually of use, access, and cost of treatment ${ }^{[18]}$. In recent years the uro-pathogens has been reported globally by development resistance to effective antibiotics previously ${ }^{[19,20]}$, and the place and time are vary susceptibility ${ }^{[21]}$. The protection of fetus and resistance development of uropathogens are two major challenges while treating UTIs in pregnancy. While prescribing antibiotics, the physicians must consider possible side effects from drugs to protect maternal and fetal safety ${ }^{[22,23]}$. The antibiotic chosen should have efficacy and low resistance rates in a given population at the same time ${ }^{[24,25]}$.

The normal vaginal, perineal, and fecal flora are cause of the UTI ${ }^{[26,27]}$. They include species of Escherichia coli, Staphylococcus aureus, Staphylococcus faecalis, Proteus mirabilis, Klebsiella species and Streptococcus species and others $^{[28]}$. The UTI causing organisms have been reported to resistance antibiotics ${ }^{[27]}$. The broad spectrum antibiotics use frequently, these resistant bacteria is mainly due to widespread use of antibiotics in people and animal feeds ${ }^{[29,28]}$. These resistance properties are easily transferred among the bacteria of different genera through plasmids and other means ${ }^{[27]}$. Although they are still seen in community acquired UTI with an increasing presence of gram-positive cocci like Staphylococci and gram negative organisms like Klebsiella becoming more frequent and the resistance of antibiotics are mostly observed in hospital $^{[30,31]}$.

Without the use of a urine culture or susceptibility testing to guide therapy, current management of UTIs are usually empirical. However, the community acquired many infections, antimicrobial resistance between the pathogens that cause UTIs is increasing and is a major health problem in the treatment of $\mathrm{UTI}^{[32,33]}$. The antimicrobial resistance is growing worldwide, particularly E.coli is the dominant causative agent of UTI in pregnant women ${ }^{[34]}$.

\section{Materials \& Methods}

Different urine samples from pregnant women with or without having symptoms of UTI were collected during October 2014 to January 2016. The age of people included in the study ranged from 25-40 years. Verbal informed consent from 
target population and approval from institutional research ethical committee were obtained before starting the experiment. Female patients aged between 25-40 years with uncomplicated UTI symptoms like frequency, urgency and dysuria were included in the study. Pregnant women on antibiotics within the last 2 weeks and those who could not give consent to participate in the study were excluded. Clean catch midstream urine samples were collected into a sterile screw capped universal container by standard method. The samples were labeled and $0.2 \mathrm{mg}$ of boric acid was added to prevent the bacterial growth in urine samples. The samples were cultured on cysteinelactose electrolyte deficient agar and blood agar using a sterile $4 \mathrm{~mm}$ platinum wired calibrated loop for the isolation of microorganisms. The plates were incubated for overnight at $37{ }^{\circ} \mathrm{C}$ and the samples were considered positive when an organism was cultured at a concentration of 104 $\mathrm{CFU} / \mathrm{mL}$ which was estimated through multiplying the isolated colonies by 1000 . The isolates were identified up to the species level by standard biochemical tests ${ }^{[15]}$. Antibiotic sensitivity testing was performed by the modified disc diffusion method as per the recommendations [16]. Inoculums adjusted to $0.5 \mathrm{McF}$ arland standard was swabbed on Mueller Hinton agar plates for antibiotic sensitivity assay. Eight groups of antimicrobials such as penicillins, cephalosporins, fluoroquinolones, aminoglycosides, macrolides, lincosamides, glycopeptides and sulfonamides were selected based on frequent prescription and used in this study. Among the group, the antibiotics tested were amoxicillin $(10 \mu \mathrm{g})$, oxacillin $(10 \mu \mathrm{g})$, cloxacillin $(5 \mu \mathrm{g})$, cefotaxime $(10 \mu \mathrm{g})$, ceftriaxone $(30 \mu \mathrm{g})$, nalidixic acid (30 $\mu \mathrm{g})$, ciprofloxacin $(5 \mu \mathrm{g})$, norfloxacin $(10 \mu \mathrm{g})$, amikacin $(30 \mu \mathrm{g})$, gentamycin $(10 \mu \mathrm{g})$, erythromycin $(10 \mu \mathrm{g})$, clindamycin $(2 \mu \mathrm{g})$, vancomycin $(30 \mu \mathrm{g})$ and co-trimoxazole $(30 \mu \mathrm{g})$. Statistical analysis was done using Chi-square test and student's t-test.

\section{Results}

A total number of 288 urine sample from pregnant women were screened for bacterial contamination. The pregnant women were age from 20 to more than 40 years old. Among the 288 samples 186 urie were infected $(64.483 \%)$.It is revealed that in the age group 30-39 maximum contamination were found.(Tab-1).

Different bacteria were isolated from UTI samples Escherichia coli-113 (Fig 1), Staphylococcus aureus-94, Pseudomonass pp-76, Coagulase negative Staphylococci-69, Candida barbicans37, Klebsiellas pp-13, Proteus spp-05, Enterobacters pp-04, Streptococcus spp-03.(Tab2).

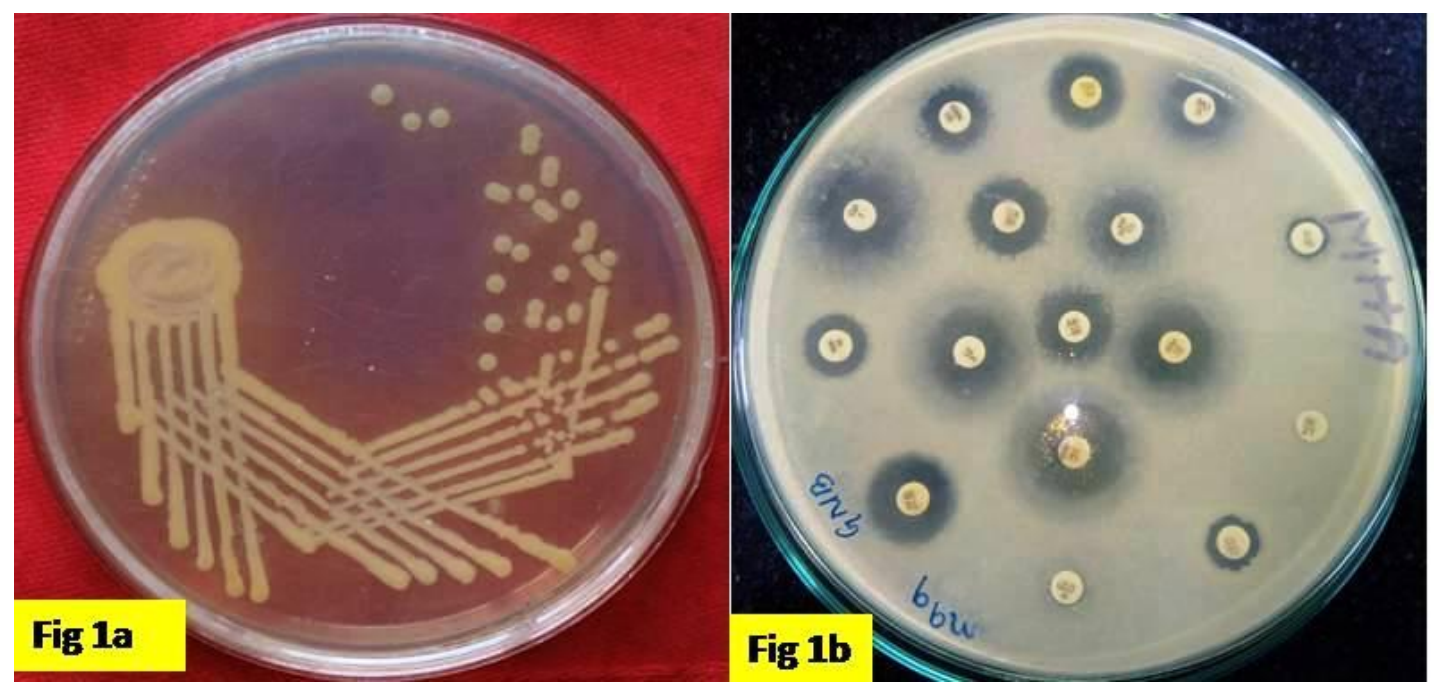

Fig 1a Pure culture of E. Coli, 1b. Antibiotic sensitivity pattern of E. coli 
All the isolated bacteria were tested for antibiotic sensitivity pattern with prescribed 51 antibiotics among them. It was revealed that NET was resistance to Escherichia coli-37.5\%, Staphylococcus aureus-23\%, Pseudomonass pp-
$50 \%$, Coagulase negative Staphylococci-50\%, Candida barbicans-20\%, Klebsiellas pp-58.3\%, Proteus spp-7.31\%, Enterobacters pp-25\% and Streptococcus spp-33.3\% respectively .Tab3(a),3(b) \& 3(c).

Table 1 Distribution of microbial isolates in the urine of pregnant women with respect to age

\begin{tabular}{|c|c|c|c|c|}
\hline Serial Number & Age range & Number examined & Number infected & Percent $(\%)$ \\
\hline 1. & $<20$ & 17 & 2 & 11.765 \\
\hline 2. & $20-29$ & 116 & 72 & 62.069 \\
\hline 3. & $30-39$ & 149 & 107 & 71.812 \\
\hline 4. & $>40$ & 6 & 5 & 83.333 \\
\hline 5. & total & 288 & 186 & 64.583 \\
\hline
\end{tabular}

Table 2 Number of organisms isolated from urine samples from pregnant women

\begin{tabular}{|l|c|c|}
\hline Microbial isolates & $\begin{array}{c}\text { Microbial isolates in } \\
\text { frequency }(\mathrm{n}=414)\end{array}$ & $\begin{array}{c}\text { Percentage of Microbial } \\
\text { isolated }\end{array}$ \\
\hline Escherichia coli & 113 & 27.29 \\
\hline Staphylococcus aureus & 94 & 22.71 \\
\hline Pseudomonass pp & 76 & 21.01 \\
\hline Coagulase negative Staphylococci & 69 & 16.67 \\
\hline Candida barbicans & 37 & 8.94 \\
\hline Klebsiellas pp & 13 & 3.14 \\
\hline Proteus spp & 5 & 1.21 \\
\hline Enterobacters pp & 4 & 0.97 \\
\hline Streptococcus spp & 3 & 0.72 \\
\hline
\end{tabular}

In this study 51antibiotics were used for UTI in pregnant women. It is revealed that Ceftriaxone (CTR) and Cefixime (CFM) Antibiotics were most resistance $39.39 \%$. However, the antibiotics
CPZ, PAZ, FUR, CD, PB, CPT, ERY, AMX, TI, $\mathrm{C}, \mathrm{RIF}, \mathrm{NAL}, \mathrm{DOR}$ and LNC were list resistance (Tab-4).

Table 3(a): Microorganism Resistance Percentage

\begin{tabular}{|c|c|c|c|c|c|c|c|c|c|c|c|c|c|c|c|c|}
\hline Microrganisms & AMK & AMC & $\mathrm{CEF}$ & GEN & NOR & NIT & PIT & LNZ & AZT & OFL & CTR & CFM & CPM & LVF & VAN & TBR \\
\hline Escherichia coli & 37.5 & 12.5 & 62.5 & 12.5 & 16.5 & 24.5 & 0 & 12.5 & 50 & 12.5 & 15 & 19.5 & 12.5 & 0 & 12.5 & 13 \\
\hline Staphylococcus aureus & 23 & 34 & 12 & 43.5 & 0 & 100 & 12 & 17 & 23 & 15 & 32 & 21 & 0 & 19 & 22 & 15 \\
\hline Pseudomonass pp & 50 & 25 & 25 & 50 & 25 & 0 & 50 & 50 & 25 & 50 & 0 & 25 & 100 & 50 & 75 & 25 \\
\hline $\begin{array}{ll}\text { Coagulase } & \text { negative } \\
\text { Staphylococci } & \end{array}$ & 50 & 25 & 25 & 50 & 25 & 100 & 0 & 25 & 0 & 25 & 50 & 0 & 50 & 25 & 50 & 75 \\
\hline Candida barbicans & 20 & 40 & 0 & 20 & 80 & 40 & 40 & 20 & 20 & 40 & 0 & 40 & 40.5 & 20 & 80 & 0 \\
\hline Klebsiellas pp & 58.3 & 41.6 & 8.3 & 58.3 & 8.3 & 16.6 & 8.3 & 8.3 & 58.3 & 8.3 & 16.6 & 27.6 & 28 & 66.6 & 8.3 & 12.5 \\
\hline Proteus spp & 7.31 & 31.7 & 19.5 & 4.87 & 78 & 12.1 & 24.3 & 0 & 0 & 58.5 & 19.5 & 29.2 & 4.8 & 4.8 & 0 & 4.8 \\
\hline Enterobacters pp & 25 & 25 & 75 & 50 & 0 & 25 & 100 & 25 & 25 & 50 & 25 & 25 & 25 & 50 & 75 & 50 \\
\hline Streptococcus spp & 33.3 & 23.3 & 33.3 & 0 & 33.3 & 26 & 33.3 & 0 & 23 & 33.3 & 62 & 42 & 0 & 46 & 12.6 & 13.5 \\
\hline
\end{tabular}

Table-3(b): Microorganism Resistance Percentage

\begin{tabular}{|c|c|c|c|c|c|c|c|c|c|c|c|c|c|c|c|c|c|c|}
\hline Microrganisms & NET & PEP & PEN & AMP & CAZ & IC & CFS & CAC & CPZ & LNC & PAZ & OXC & FUR & TGC & CD & TEC & CXM & CIS \\
\hline Escherichia coli & 12.5 & 0 & 12.5 & 0 & 12.5 & 50 & 25 & 12.5 & 12.5 & 75 & 0 & 37.5 & 0 & 75 & 37.5 & 0 & 37.5 & 12.5 \\
\hline Staphylococcus aureus & 42 & 12 & 14 & 19 & 14 & 27 & 0 & 19 & 27 & 14 & 63 & 73 & 0 & 0 & 19 & 47 & 0 & 38 \\
\hline Pseudomonass pp & 25 & 50 & 25 & 50 & 0 & 25 & 25 & 50 & 0 & 25 & 75 & 50 & 0 & 25 & 0 & 25 & 50 & 0 \\
\hline $\begin{array}{l}\text { Coagulase negative } \\
\text { Staphylococci }\end{array}$ & 75 & 0 & 12.5 & 50 & 25 & 25 & 50 & 25 & 0 & 12.5 & 25 & 75 & 12.5 & 0 & 50 & 25 & 25 & 75 \\
\hline Candida barbicans & 20 & 20 & 60 & 0 & 20 & 0 & 40 & 20 & 60 & 0 & 80 & 0 & 20 & 40 & 60 & 0 & 20 & 20 \\
\hline Klebsiellas pp & 16.6 & 8.3 & 44 & 8.3 & 33.2 & 8.3 & 0 & 33.2 & 16.6 & 8.3 & 0 & 74.3 & 8.3 & 16.6 & 0 & 8.3 & 8.3 & 8.3 \\
\hline Proteus spp & 4.8 & 21.9 & 0 & 4.8 & 17 & 0 & 9.75 & 14.6 & 9.75 & 28.8 & 9.6 & 2.43 & 0 & 19.2 & 43.2 & 4.8 & 4.87 & 4.87 \\
\hline Enterobacters pp & 12.5 & 12.5 & 50 & 0 & 50 & 20 & 0 & 25 & 25 & 75 & 0 & 100 & 25 & 0 & 75 & 50 & 25 & 0 \\
\hline Streptococcus spp & 33.3 & 0 & $\begin{array}{ll}33.3 \\
\end{array}$ & 66.6 & 33.3 & 0 & 11.1 & 33.3 & 0 & 19.6 & 43.3 & 23.3 & 11.1 & 13.3 & 0 & 33.3 & 66.6 & 66.6 \\
\hline
\end{tabular}


Table-3(c): Microorganism Resistance Percentage

\begin{tabular}{|l|c|c|c|c|c|c|c|c|c|c|c|c|c|c|c|c|c|}
\hline Microrganisms & IMP & CIP & PB & MRP & CPT & ERY & CFP & COT & CIT & COL & AMX & CN & TI & C & RIF & NAL & DOR \\
\hline Escherichia coli & 12.5 & 62.5 & 12 & 0 & 25 & 12.5 & 12.5 & 50 & 0 & 12.5 & 12.5 & 50 & 62.5 & 75 & 0 & 12.5 & 50 \\
\hline Staphylococcus aureus & 14 & 19 & 0 & 17 & 13.5 & 29.6 & 43.5 & 100 & 0 & 48 & 23 & 13 & 16 & 0 & 19 & 34 & 0 \\
\hline Pseudomonass pp & 0 & 50 & 0 & 25 & 0 & 50 & 0 & 12.5 & 25 & 25 & 75 & 0 & 12.5 & 0 & 12.5 & 0 & 12.5 \\
\hline $\begin{array}{l}\text { Coagulase } \\
\text { Staphylococci }\end{array}$ & 12.5 & 0 & 25 & 50 & 50 & 0 & 12.5 & 100 & 12.5 & 50 & 50 & 12.5 & 12.5 & 0 & 50 & 0 & 50 \\
\hline Candida barbicans & 60 & 20 & 0 & 40 & 20 & 20 & 60 & 80 & 0 & 20 & 0 & 40 & 0 & 40 & 0 & 60 & 20 \\
\hline Klebsiellas pp & 49.8 & 66.6 & 8.3 & 8.3 & 0 & 16.6 & 24.9 & 8.3 & 8.3 & 0 & 8.3 & 0 & 33.2 & 0 & 49.8 & 8.3 & 0 \\
\hline Proteus spp & 2.43 & 26.8 & 0 & 2.43 & 43.9 & 19.4 & 0 & 43.9 & 2.43 & 2.43 & 0 & 19.4 & 43.9 & 2.43 & 26.8 & 19.4 & 2.43 \\
\hline Enterobacters pp & 50 & 12.5 & 12.5 & 0 & 75 & 50 & 50 & 25 & 0 & 12.5 & 25 & 25 & 12.5 & 0 & 12.5 & 50 & 50 \\
\hline Streptococcus spp & 11.1 & 33.3 & 0 & 66.6 & 33.3 & 11.1 & 0 & 33.3 & 22.2 & 0 & 23.3 & 0 & 0 & 33.3 & 66.6 & 11.1 & 33.3 \\
\hline
\end{tabular}

Table-4: Antibiotics Resistance And Percentage

\begin{tabular}{|l|c|c|c|c|c|c|c|}
\hline SL.NO. & Antibiotics & Resistance & $\%$ Of Resistance & 26 & PAZ & 0 & 0 \\
\hline 1 & AMK & 19 & 14.28 & 27 & OXC & 5 & 0 \\
\hline 2 & AMC & 20 & 15.03 & 28 & FUR & 0 & 3.75 \\
\hline 3 & CEF & 17 & 12.78 & 29 & TGC & 1 & 0 \\
\hline 4 & GEN & 11 & 8.27 & 30 & CD & 0 & 0.75 \\
\hline 5 & NOR & 39 & 29.32 & 31 & TEC & 1 & 0 \\
\hline 6 & NIT & 13 & 9.77 & 32 & CXM & 2 & 0.75 \\
\hline 7 & PIT & 18 & 13.53 & 33 & CIS & 4 & 1.5 \\
\hline 8 & LNZ & 1 & 0.75 & 34 & IMP & 1 & 3 \\
\hline 9 & AZT & 11 & 8.27 & 35 & CIP & 28 & 0.75 \\
\hline 10 & OFL & 30 & 22.55 & 6 & PB & 0 & 21.05 \\
\hline 11 & CTR & 13 & 39.39 & 37 & MRP & 2 & 0 \\
\hline 12 & CFM & 13 & 39.39 & 38 & CPT & 0 & 1.5 \\
\hline 13 & CPM & 7 & 5.26 & 39 & ERY & 0 & 0 \\
\hline 14 & LVF & 10 & 7.51 & 40 & CFP & 1 & 0 \\
\hline 15 & VAN & 2 & 1.5 & 41 & COT & 25 & 0.75 \\
\hline 16 & TBR & 1 & 0.75 & 42 & CIT & 3 & 18.79 \\
\hline 17 & NET & 6 & 0.75 & 43 & COL & 2 & 2.25 \\
\hline 18 & PEP & 18 & 4.51 & 44 & AMX & 0 & 1.5 \\
\hline 19 & PEN & 9 & 13.53 & 45 & CN & 4 & 0 \\
\hline 20 & AMP & 1 & 6.76 & 46 & TI & 0 & 3 \\
\hline 21 & CAZ & 9 & 0.75 & 47 & C & 0 & 0 \\
\hline 22 & IC & 1 & 6.76 & 48 & RIF & 0 & 0 \\
\hline 23 & CFS & 7 & 0.75 & 49 & NAL & 0 & 0 \\
\hline 24 & CAC & 9 & 5.26 & 50 & DOR & 0 & 0 \\
\hline 25 & CPZ & 0 & 6.76 & 51 & LNC & 0 & 0 \\
\hline & & & & & & & \\
\hline
\end{tabular}

\section{Discussion}

Clinical diagnosis and empiric antibiotic therapy of UTI among pregnant women lead to massive antibiotic misuse, inadvertently rendering the first line of drugs ineffective. Diagnostic tests, easy to carry out and evaluate also by inexperienced staff, are therefore necessary. In this study, we investigated a total of 2562 patients for bacteriuria. Of these 1621 were urine samples from pregnant women in IMS and SUM Hospital, Bhubaneswar with and without UTI symptoms, in order to verify the prevalence of cystitis and ABU. Because physiological changes during pregnancy might cause symptoms similar to cystitis, a low frequency of bacteriologically confirmed UTI among patients with symptoms was anticipated. Although the prevalence of UTI among pregnant women in our study is close to those reported regionally ${ }^{[17,18]}$, it is particularly alarming that our observations show that as many as $96 \%$ of patients are routinely treated with antibiotic therapy that they do not require. The positive correlation between antibiotic misuse and development of drug resistance ${ }^{[35]}$ may in part explain the high antibiotic resistance seen in developing countries as we and others have demonstrated $^{[36,37]}$. To improve the diagnosis, we evaluated nitrite and leukocyte esterase tests and a simplified culture method, dipslide. In line with previous reports, nitrite and leukocyte esterase tests alone demonstrated insufficient diagnostic value in this study. The combined results of these 2 tests demonstrated acceptable specificity and low sensitivity but were still of limited value. Although the nitrite test had high specificity, the sensitivity was low, especially among pregnant 
women, which is line with other studies ${ }^{[38]}$ and may relate to frequent urination leading to reduced bacterial concentration. Further, presence of vitamin $\mathrm{C}$ in urine is another confounding factor $^{[39]}$, which cannot be ruled out among our patients. During pregnancy, the specificity of urinary leukocytes as an indicator for bacteriuria per se might be questionable because of elevated urine specific gravity that may give false negative results ${ }^{[39]}$. Similarly, low sensitivity was obtained in urine samples collected from non -pregnant women. Moreover, false negative results have been reported with common antibiotics like cephalosporins $^{[40]}$. Also, the poor correlation between enzymatic activity and microscopic detection of leukocytes in urine is a major concern. Even though microscopy is regarded as the golden standard for this analysis, high variability between replicate leukocyte counts suggest that the analysis suffers substantial draw backs, when performed in the clinical setting. Moreover, false negative results might be due to cell lyses if analysis is delayed. In addition, microscopic analyses of leukocyturia are time consuming if carried out with care. Taken together, detection of leukocytes especially using microscopy but also leukocyte esterase test are poor markers for the detection of UTI particularly among pregnant women and is in line with previous studied $^{[41,42]}$. The use of dip slide culture was, on the other hand, particularly rewarding in urine samples with no bacterial growth. These samples constitute the majority and were correctly diagnosed. Therefore, even in the hands of inexperienced healthcare providers this would substantially decrease the antibiotic use. The identification of E. coli and other Enterobacteriaceae was also satisfactorily evaluated with the dipslide test even with inexperienced medical doctors and nurses. This can in part be attributed to the E. coli-specific agar containing $\beta$ glucuronidase, resulting in a color change. However, false negative results can occur in rare cases if the strain lacks the enzyme ${ }^{[13]}$. Also, false positive results may occur among Citrobacter spp. ${ }^{[43]}$. Interestingly, we demonstrated that nurses with very limited training, and with no access to a professional microbiological laboratory or expert personnel, correctly diagnosed E. coli UTI in almost $80 \%$ of cases. To accurately define mixed fecal flora using dip slide ${ }^{[44]}$ was problematic, and the nurses prescribed antibiotics in $91 \%$ of such cases. In the current study, contamination was observed in 5\%, whereas others have demonstrated up to $10 \%{ }^{[45]}$, which would implicate risk of over interpretation. Another drawback for dipslide culture especially among pregnant women is the failure to detect GBS, which is in line with observations made employing 2-medium dip slides ${ }^{[46]}$. Treatment recommendations differ between countries. In IMS and SUM Hospital, Bhubaneswar, pregnant women with UTI receive amoxicillin, amoxicillin/clavulanic acid, or cephalexin without laboratory verification and susceptibility testing, whereas nitrofurantoin or amoxicillin are recommended in Kenya, Tanzania, and Rwanda [47-49]. The use of nitrofurantoin and pivmecillinam are also recommended by international guidelines ${ }^{[50]}$. In our study, E. coli was highly resistant to many of the drugs used for treatment of pregnant women like $66 \%$ resistant to ampicillin (amoxacillin), 38\% to amoxicillin/ clavulanic acid, and $18 \%$ to cephalexin, which decreases the treatment options. In addition, we report a high ESBL prevalence (18\%), even higher than the general ESBL prevalence in Africa $^{[51]}$. As a consequence, almost all pregnant women presenting with UTI symptoms will receive antibiotics either not indicated at all or with high risk of being ineffective. International and East African regional guidelines recommend nitrofurantoin and during the last 2 trimesters also pivmecillinam. An appropriate alternative would therefore be nitrofurantoin or pivmecillinam, where low resistance is observed ${ }^{[47-50]}$.

The high antibiotic consumption proves the importance of continuously reviewing the susceptibility pattern of uropathogens. It also calls for diagnostic methods possible to use in clinics 
with no access to laboratory service. To the best of our knowledge, this is the first study investigating the practicability of the dip slide culture test under clinically relevant conditions in a low-resource country. To introduce dip slide in clinical routine, possibly supported with nitrite and leukocyte esterase tests would substantially reduce the misuse of antibiotics. Healthcare professionals can learn to correctly evaluate samples with no bacterial growth. Compared to clinical diagnosis alone, the use of dip slide would imply substantially decreased antibiotic consumption and as a consequence decreased risk for development of resistance among bacterial pathogens. The massive amount of saved antibiotics might furthermore outweigh, at least in part, the costs associated with the increased diagnostic efforts.

\section{Conclusions}

In many clinicians choose for the strip urinalysis method for assessing urine in pregnant women and in many hospitals in developing countries, routine urine culture test is not carried out for antenatal patients. Which is usually seen in the case of culture test the true picture of such urine specimen cannot be fully assessed as the strip cannot quantify the extent of infection in such a patient as well as provide antimicrobial therapy. Usually antibiotics are given empirically before the laboratory the urine culture results are available. Their antibiotic susceptibility pattern is mandatory to ensure appropriate therapy, current knowledge of the organism that causes UTIs and. Therefore, The antibacterial activity is needed to periodic evaluation and update information. Therefore, including their antibiotic susceptibility pattern isolated from pregnant women with urinary tract infection to readdress this situation.

\section{Reference}

1. Fiadjoe P, Kannan K, Rane A. Maternal Urological Problems Inpregnancy. Eur J Obstet Gynecol Reprod Biol. 2010;152:13-7.
2. Herráiz Ma, Hernández A, Asenjo E, Herráiz I. Urinary Tractinfections In Pregnancy. Enferm Infecc Microbiol Clin.2005;23:40-6.

3. Figueiredo A, Gomes G, Campos A. Urinary Tract Infection Inpregnancy: Diagnosis, Treatment And Prevention. Acta Obstetginecol Port. 2012;6:124-33.

4. Hummers-Pradier E, Kochen Mm. Urinary Tract Infections In Adult General Practice Patients.Br J Gen Pract 2002; 52(482):752-761.

5. Mclaughlin Sp, Carson Cc. Urinary Tract Infections In Women. Med Clin North Am 2004; 88: 417-429.

6. Addo Vn. Urinary Tract Infection In Pregnancy. In: Kwawukume Ey, Emuveyan Ee, Editors. Comprehensive Obstetrics In The Tropics. Dansoman: Asante And Hittscher Printing Press Limited; 2002, P. 261-267.

7. Le J, Briggs Gg, Mckeown A, Bustillo G. Urinary Tract Infections During Pregnancy. Ann Pharmacother 2004; 38(10):1692-1701.

8. Jeyabalan A, Lain Ky. Anatomic And Functional Changes Of The Upper Urinary Tract During Pregnancy. Urol Clin North Am 2007; 34: 1-6.

9. Gilbert Nm, O’brein Vp, Hultgren S, Macones G, Lewis Wg, Lewis Al. Urinary Tract Infection As A Preventable Cause Of Pregnancy Complications: Opportunities, Challenges And Aglobal Call To Action. Glob Adv Health Med 2013; 2: 59-69.

10. Demilie T, Beyene G, Melaku S, Tsegaye W. Diagnostic Accuracy Of Rapid Urine Dipstick Test To Predict Urinary Tract Infection Among Pregnant Women In Felege Hiwot Referral Hospital, Bahir Dar, North West Ethiopia. Bmc Res Notes 2014; 7: 481.

11. Mittal P, Wing Da: Urinary Tract Infections In Pregnancy. Clin Perinatol 2005, 32:749-7641. 
12. Gupta K, Hooton Tm, Naber Kg, Wullt B, Colgan R, Miller Lg, Moran Gj, Nicolle Le, Raz R, Schaeffer Aj, Soper De, Infectious Diseases Society Of America, European Society For Microbiology And Infectious Diseases. 2011.

13. International Clinical Practice Guidelines For The Treatment Of Acute Uncomplicated Cystitis And Pyelonephritis In Women: A 2010 Update By The Infectious Diseases Society Of America And The European Society For Microbiology And Infectious Diseases. Clin Infect Dis 52:E103-E120.

14. Sanchez Gv, Master Rn, Bordon J. 2011. Trimethoprimsulfamethoxazole May No Longer Be Acceptable For The Treatment Of Acute Uncomplicated Cystitis In The United States. Clin Infect Dis 53:316-317.

15. Sanchez Gv, Master Rn, Karlowsky Ja, Bordon Jm. 2012. In Vitro Antimicrobial Resistance Of Urinary Escherichia Coli Isolates Among U.S. Outpatients From 2000 To 2010. Antimicrob Agents Chemother 56:2181-2183.

16. Sader Hs, Flamm Rk, Jones Rn. 2014. Frequency Of Occurrence And Antimicrobial Susceptibility Of GramNegative Bacteremia Isolates In Patients With Urinary Tract Infection: Results From United States And European Hospitals (2009 -2011). J Chemother 26:133-138.

17. Zilberberg Md, Shorr Af. 2013. Secular Trends In Gram-Negative Resistance Among Urinary Tract Infection Hospitalizations In The United States, 2000-2009. Infect Control Hosp Epidemiol 34:940-946.

18. Macleon Ab. Urinary Tract Infection In Pregnancy. Int Jantimicrob Agents. 2001;17:273-6. 18. Krcmery S, Hromec J, Demesova D. Treatment Of Lowerurinary Tract Infection In Pregnancy. Int $\mathbf{J}$ Antimicrob Agents.2001;17:279-82.
19. Shigemura K, Tanaka K, Adachi M, Yamshita M, Arakawa S, Fujisawa M. Chronological Change Of Antibiotic Use And Antibiotic Resistance In Escherichia Coli Causing Urinary Tract Infections. J Infect Dis Chemother 2011; 17: 646-651.

20. Gupta K, Hooton Tm, Stamm We. Increasing Antimicrobial Resistance And The Management Of Uncomplicated Community acquired Urinary Tract Infections. Ann Int Med 2001; 135(1):4150.

21. Sefton Am. The Impact Of Resistance On The Management Of Urinary Tract Infections. Int J Antimicrob Agents 2000; 16(4):489-491.

22. Mitchell Aa, Gilboa Sm, Werler Mm, Kelley Ke, Louik C, Hernández-Díaz S, Et Al. Medication Use During Pregnancy, With Particular Focus On Prescription Drugs: 1976-2008. Am J Obstet Gynecol 2011; Doi: 10.1016/J.Ajog.2011.02.029.

23. Kladensky J. [Urinary Tract Infections In Pregnancy: When To Treat, How To Treat, And What To Treat With]. Ceska Gynekol 2012;77: 167-171. Czech.

24. Nicoll Le. Short-Term Therapy For Urinary Tract Infections:Success And Failure. Int J Antimicrob Agents 2008; 31(Suppl 1):S40-S45.

25. Schenkel Df, Dalle J, Antonello Vs. [Microbial Etiology And Susceptibility Of Community Urinary Tract Infections During Pregnancy In The South Of Brazil]. Rev Bras Ginecol Obstet 2014; 36: 102-106. Portuguese.

26. Cunningham Fg, Gant Nf, Leveno $\mathrm{Kj}$, Gilstrap Lc Iii, Hauth Jc, Wenstrom Kd. Renal And Urinary Tract Disorders. In: Andrea Seils, Noujaim Sr, Daris K, Editors. Williams Obstetrics. 21st Ed. New York: Mcgraw-Hill Medical Publishing Divsion; 2001:1251-1272.

27. Arias F. Abnormalities Of The Urinary System During Pregnancy. In: Daftary Sn, 
Bhide Ag, Editors. Practical Guide To High Risk Pregnancy And Delivery. A South Asian Perspective. 3rd Ed. New Delhi: Elsevier; 2008:489-505.

28. Abdul If, Onile Ba. Bacterial Isolates From Urine Of Women In Ilorin And Their Antibiotic Susceptibility Patterns. Trop J Obstet Gynaecol. 2001;18(2):6165.

29. Ezechi Oc, Fasubaa Ob, Dare Fo. Antibiotic Sensitivity Patterns Of Microbial Isolates From Urine Of Pregnant Women With Urinary Tract Infections. Trop J Obstet Gynaecol. 2003;20(2):113115.

30. Alausa Ko, Montefiore D, Sobayo E. Problems In The Diagnosis Of Urinary Tract Infections. Niger Med J. 1979;9:107-111.

31. Onyemenem Tn, Ekweozor Cc. Urinary Tract Infection In Ibadan: Causative Organisms And Antimicrobial Sensitivity Patterns. Afr J Med Sci. 1996;25:165-169.

32. Gupta K, Hooton T M, Stamm We. Increasing Antimicrobial Resistance And The Management Of Uncomplicated Community-Acquired Urinary Tract Infections. Ann Intern Med. 2001; 135: 4150.

33. Mordi Rm, Erah Po. Susceptibility Of Common Urinary Isolates To The Commonly Used Antibiotics In A Tertiary Hospital In Southern Nigeria. Afr $J$ Biotechnol. 2006; 5: 1067-1071.

34. Chakupurakal R, Ahmed M, Sobithadevi Dn, Chinnappan S, Reynolds T. Urinary Tract Pathogens And Resistance Pattern. $J$ Clin Pathol. 2010; 63: 652-654.

35. Goossens H, Ferech M, Vander Stichele R, Elseviers M. ESAC Project Group. Outpatient antibiotic use in Europe and association with resistance: a crossnational database study. Lancet. 2005; 365:579-87.
36. Ramos NL, Sekikubo M, Dzung DT. Uropathogenic Escherichia coli isolates from pregnant women in different countries. J Clin Microbiol. 2012; 50:3569-74.

37. Del Arco A, Tortajada B, de la Torre J. The impact of an antimicrobial stewardship programme on the use of antimicrobials and the evolution of drug resistance. Eur J Clin Microbiol Infect Dis. 2015; 34:247-51.

38. Demilie T, Beyene G, Melaku S, Tsegaye W. Diagnostic accuracy of rapid urine dipstick test to predict urinary tract infection among pregnant women in Felege Hiwot Referral Hospital, Bahir Dar, North West Ethiopia. BMC Res Notes. 2014; 7:481.

39. Simerville JA, Maxted WC, Pahira JJ. Urinalysis: a comprehensive review. Am Fam Physician. 2005; 71:1153-62.

40. Beer JH, Vogt A, Neftel K, Cottagnoud P. False positive results for leucocytes in urine dipstick test with common antibiotics. BMJ. 1996; 313:25.

41. Kupelian AS, Horsley H, Khasriya R Discrediting microscopic pyuria and leucocyte esterase as diagnostic surrogates for infection in patients with lower urinary tract symptoms: results from a clinical and laboratory evaluation. BJU Int. 2013; 112:231-8.

42. Leman P. Validity of urinalysis and microscopy for detecting urinary tract infection in the emergency department. Eur J Emerg Med. 2002; 9:141-7.

43. Perez JL, Berrocal CI, Berrocal L. Evaluation of a commercial betaglucuronidase test for the rapid and economical identification of Escherichia coli. J Appl Bacteriol. 1986; 61:541-5.

44. Schneeberger C, van den Heuvel ER, Erwich JJ, Stolk RP, Visser CE, Geerlings SE. Contamination rates of three urinesampling methods to assess bacteriuria in 
pregnant women. Obstet Gynecol. 2013; 121:299-305.

45. Palmqvist E, Aspevall O, Burman E, Nordin G, Svahn A, Forsum U. Difficulties for primary health care staff in interpreting bacterial findings on a device for simplified urinary culture. Scand J Clin Lab Invest. 2008; 68:312-6.

46. Mignini L, Carroli G, Abalos E, Widmer M, Amigot S, Nardin JM et al. World Health Organization Asymptomatic Bacteriuria Trial Group. Accuracy of diagnostic tests to detect asymptomatic bacteriuria during pregnancy. Obstet Gynecol. 2009; 113:346-52.

47. Director Health Services K. Clinical guidelines for the diagnosis and treatment of common conditions in Kenya. 2002; $18(2,3)$.

48. Ministry of Health and Social Welfare TURoT. Standard Treatment Guidelines and Essential Medicines List. 2013, 85.

49. Ministry of Health Kigali R. Gynecology and Obstetrics Clinical protocols and treatment guidelines. 2012, 71-4.

50. Wagenlehner FM, Schmiemann G, Hoyme U. National S3 guideline on uncomplicated urinary tract infection: recommendations for treatment and management of uncomplicated community-acquired bacterial urinary tract infections in adult patients. Urologe A. 2011; 50:153-69.

51. Tansarli GS, Poulikakos P, Kapaskelis A, Falagas ME. Proportion of extendedspectrum $\beta$-lactamase (ESBL)-producing isolates among Enterobacteriaceae in Africa: evaluation of the evidencesystematic review. J Antimicrob Chemother. 2014; 69:1177-84. 